\title{
RC Hovercraft: An I-Bylogical Enzyme (I-BE) Biosensor Carrier
}

\author{
Rinta Kridalukmana ${ }^{1}$, Budi Cahyo S. P. ${ }^{2}$, Deddy Kurniawan $W^{3}$, Fahmi Arifan ${ }^{4}$ \\ ${ }^{1,2}$ Departement of Computer System, Faculty of Engineering, Diponegoro University, Indonesia \\ ${ }^{3,4}$ Diplome Program of Chemical Engineering, Faculty of Engineering, Diponegoro University, Indonesia
}

\begin{abstract}
Article Info
Article history:

Received Sep 1, 2016

Revised Jun 9, 2017

Accepted Jun 23, 2017

\section{Keyword:}

Biosensor carrier

Hovercraft

ABSTRACT

In this research, a hovercraft was developed as a transportation tool to carry an I-Bylogical Enzyme (I-BE) biosensor. The main function of the biosensor is to measure the level of dangerous chemical materials from factory's liquid waste. Hence, fiber and acrylic materials, that widely known for its resistance to chemical reaction, are needed to build the hovercraft. By using Atmega 8535 microcontroller and Arduino Uno board, a remote control was choosen to navigate hovercraft's movement with support of 6 channels Transmitter Receiver. As a result, after series of tests that were carried out, indicate that the hovercraft's prototype was found to meet design and requirements expectation.
\end{abstract}

I-BE biosensor

Remote control

Copyright $@ 2017$ Institute of Advanced Engineering and Science. All rights reserved.

\section{Corresponding Author:}

Rinta Kridalukmana and Budi Cahyo S.P.,

Departement of Computer System, Faculty of Engineering

Diponegoro University,

Prof. Soedharto Street, Tembalang, Semarang, Central Java, 50275, Indonesia.

Email: rintakrida, budi.cahyo@ce.undip.ac.id

\section{INTRODUCTION}

Environment profanation is often related to industries that use dangerous chemical materials without conducting waste treatment process properly so that those materials cannot be disassembled by microorganism in its disposal places and endanger our environment. Furthermore, in the developing countries, such as Indonesia, poor supervision to environment pollution, especially after the waste is sent to the nature, is mostly because the lack of supporting technology to help the local government in reaching locations that are contaminated with dangerous chemical materials. Latest transporter technologies, such as drone and hovercraft, can be a possible option to carry a measuring instrument easier to difficult locations. Yet, so far, there are only few efforts from researchers attempting to utilize those transporter technologies to assist nature pollution measurement. Hence, developing such kind of tools is crucial to make contribution in actualizing environmental sustainability.

Regarding to these problems, there are several researches that focused on developing carriers to transport environment sensing equipments such as sensors and camera. Hardin and Jensen [1] discussed about challenges and opportunities to use unmanned aerial vehicles (UAV), also well-known as drone, in environmental remote sensing. In their paper, they explained that the limit of on-board power and hostal natural environment are the essential problems when developing the vehivles. Meanwhile, Watts et al. [2] stated that it required a dedicated control system to develop large UAV and a ground-control station in small UAV. Watts also recommended the utilization of drone in air quality monitoring, groundwater discharge monitoring, forest health monitoring, and wheat crop as suggested by Lelong et al. in [3], then transportation agencies [4] and river patrols [5]. Since drone can be classified as a flying object carrier, it has lack of capability in exploring water environment such as river and swamp. For this purpose, a hovercraft is more 
suitable of traveling over the water with the support of air by fan. In addition, this vehicle can also be used on the surface of ice, mud, and on all kind of surfaces [6]. The design and development of hovercraft were reviewed by Dhale et al. in [6] and they stated that propulsion and lift are the main principles on which hovercraft work. However, lift is the main factor because it helps the vehicle to ride. According to Dhale et al., since there are various conditions of water environment, hovercraft movement in stable direction may face number of problems.

Hence, in this research, stability problems were placed as main issues when developing the hovercraft. In Dhale et al.'s research [6], cushion pressure was simply generated from total weight per area of cushion without considering the weight of each component on each spot of hovercraft. As a result, the hovercraft become unstable while doing maneuver. To reduce instability problems, there are several additional considerations used in this research, such as determining proper place for each hovercraft components to keep hovercraft in balance, optimizing physical design of the developed hovercraft, and material selection.

Considering the capability of hovercraft, this research aims to develop a remote control (RC) hovercraft vehicles equipped with I-Biologycal Enzyme (I-BE) Biosensors. Biosensor is an analytical tool that convert biochemical signal using tranducer [7], [8] to deliver information about the level of a particular chemical substance in an environment such as water and air. As I-BE biosensor's carrier, the hovercraft is designed with strong lift power to transport biosensor over the water without sacrificing its stability and can be controlled remotely, up to 1500 meters in distance in non-barriers area. In addition, with its light materials (fiber), this vehicle can save battery consume with travel time duration up to 20 minutes.

The rest of this paper is organized as follows: Section 2 and 3 present literature review and research method, respectively. Section 4 discusses about research result while conclusions are drawn and suggested respectively in Section 5.

\section{HOVERCRAFT PRINCIPLE}

A hovercraft is a self-propelled vehicle, dynamically supported by a self-generated cushion of slow moving, high pressure air which is ejected against the surface below and contained within a flexible skirt such that is totally amphibious and has some ability to travel over less than perfect surfaces [9]. Basically, hovercraft float over the ground surface on a cushion of air which is provided by the lift fan [10]. The cushion pressure eliminates all kind of friction and eases of the movement of hovercraft [6] and the pressure stability maintains sufficient lift [9]. Horizontal divider seperates the air generated from propeller into pressurized air used for the air cushion while the momentum used for thrust. Due to movement of air, the skirt gets inflated and the body is pushed and lifted when the lift force bigger that the weight of the body. The extended skirt provides containment, improves balance and makes the craft possible to travel on varied terrain. After the craft is lifted, an incorporated blower in thrust engine exerts air in backward direction. To control direction of the craft to move forward, backward, right and left, microcontroller is used. This type of vehicle can equally ride over ice, water, marsh, or relatively level land [11]. Because there is no direct contiguity between hovercraft and the ground surface, the friction will decrease so that hovercraft can move with a high speed.

There are four main concerns when developing a hovercraft: the hull, center of gravity, lift system, and the skirt [10]. The hull's design depends on the load that will be carried by the hovercraft which determines the dimension of the hull. After knowing the load of hovercraft, it is necessary to layout position of each load to get the center of gravity and to calculate the dead weight on the hull. Once the dead weight is determined, the lift system needs to be set so that it can generate proper pressure to lift the hovercraft. Then, the skirt must be able to sustain the pressure needed and push the craft up. As an unmanned vehicle, commonly hovercraft can be controlled by remote control or self-driving, using a neural network navigation technique [12]. Moreover, several approaches can be utilized regarding to enhance speed control such as proportional integral (PI), proportional integral deritative (PID), Fuzzy Logic Controller or combination between them [13].

\section{RESEARCH METHOD}

\subsection{General Requirements and Materials Selection}

Mainly, the hovercraft is designed to carry a two kilograms I-Bylogical Enzyme (I-BE) biosensor which is used to measure the level of water pollution from factory's liquid waste. Hence, the hovercraft's ability to float over the water surface, especially on a river or mere. By considering the wide of the measured area, the hovercraft should be able to be controlled remotely and in this case, it is set to 1000 meters in distance. To save battery consumption and to increase its maneuvers ability, light and strong materials, fiber 
and acrylic, are selected as main materials to build the hovercraft. Moreover, there are several advantages by using those materials, such as low-cost, can be acquired easily, not reacted to the sunlight, non-toxic, resistant to chemical reaction, and easy to maintain.

\subsection{Hardware Design}

Atmega 8535 is an 8-bit microcontroller that is attached in the hovercraft as a central processing unit (CPU) of hovercraft system and is placed on Arduino UNO board. Commands from remote control is transmitted and received by 6 channels Transmitter Receiver, and in this case, it is only three channels used to send signals to CPU and received by Arduino pin interface 3, 2, and 7. Meanwhile, Arduino pin interface 9, 6, and 5 is connected to servo, Electric Speed Control (ESC) Thrust, and ESC hover respectively which are used to control the hovercraft's movement. Furthermore, the detail information about relation between Arduino pin interface and other components's pin can be seen in Table 1. Next, servo is used to direct the hovercraft turn left and right while propeller thrust to make hovercraft to move forward and backward. Then, to make the hovercraft float over the surface of the water, this function is served by propeller hover. The relation between components in the hovercraft can be shown in Figure 1.

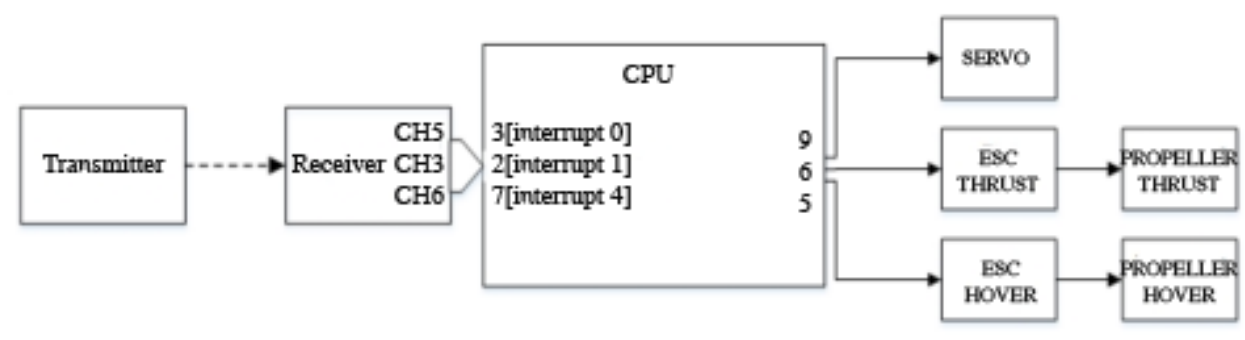

Figure 1. Hardware Block Diagram

Table 1. Relation between Interface Pin of Arduino and Components

\begin{tabular}{cc}
\hline Arduino Pin Interface & Component Pin Interface \\
\hline 0 (RX0) & USB Serial \\
1 (TX0) & USB Serial \\
2 (Interrupt 0) & CH5 Receiver Channel \\
3 (Interrupt 1) & CH3 Receiver Channel \\
4 & Servo \\
5 & ESC Hover \\
6 & ESC Thrust \\
7 (Interrupt 5) & CH3 Receiver \\
\hline
\end{tabular}

\subsection{Microcontroller Programming}

Initially, the microcontroller in the hovercraft is set to receive signals from transmitter and passes the signals through hover, threst and steering channel. Afterware, these signals are processed and is sent to each related propeller and servo to control hovercraft's movement based on transmitter's commands. For more detail, the microcontroller program flowchart can be seen in Figure 2.

\section{RESULTS AND ANALYSIS}

A unit testing is intended to examine wheter the hovercraft's hardware system is to work properly as it is designed. The hardware system needs a 11 Volt DC input that is supplied utilizing Li-Po batteray. Firstly, the examination is to check the components' communication on the electronic boards. If there is no short circuit, the light-emitting diode (LED) lamp will on. Next, the testing is focused on controlling the hovercraft by its remote control. As mentioned previously, although there are six available channels in the transmitter-receiver, the hovercraft's control only needs three channels $(\mathrm{CH} 3, \mathrm{CH} 5$, and $\mathrm{CH} 6)$. Generally, each channel detects signals from five states remote control sticks positions: bottom, top, middle, left and right. The combination of signals received from each channel and the hovercraft's response are described in Table 2. 
Table 2. Manual Control Response Testing

\begin{tabular}{|c|c|c|c|}
\hline Hover $\mathrm{CH} 3$ & Thrust CH5 & Rudder CH6 & Response \\
\hline Bottom & Middle & Middle & Object still, not moving \\
\hline Middle - Top & Middle & Middle & $\begin{array}{l}\text { Object float, floating power increase when } \\
\text { transmiter position move to upper }\end{array}$ \\
\hline Middle - Top & Middle - Top & Middle & Object floating straight forward \\
\hline Middle - Top & Middle - Top & Left & Object floating forward and turn left \\
\hline Middle - Top & Middle - Top & Right & Object floating forward and turn right \\
\hline Middle - Top & Middle - Bottom & Left & Object steping back and turn left \\
\hline Middle - Top & Middle - Bottom & Right & Object steping back and turn right \\
\hline Bottom & $\mathrm{X}$ & $\mathrm{X}$ & Object still, not moving \\
\hline
\end{tabular}



Figure 2. System Flowchart

After control response testing stage, hovercraft straight speed testing is conducted. The aim of this test is to calculate the average speed of the hovercraft. In this stage, from five times trials, by moving the hovercraft 10 meters in distance, it can be derived that the average speed is approximately 0.453 meter/second (see Table 3).

Table 3. Straight Speed Testing

\begin{tabular}{ccc}
\hline $\begin{array}{c}\text { Distance } \\
\text { (meters) }\end{array}$ & Time (seconds) & $\begin{array}{c}\text { Speed } \\
\text { (meter/second) }\end{array}$ \\
\hline 10 & 22.52 & 0.444 \\
10 & 20.63 & 0.484 \\
10 & 23.73 & 0.421 \\
10 & 22.11 & 0.452 \\
10 & 21.37 & 0.467 \\
& Average Speed $=$ & 0.453 \\
\hline
\end{tabular}




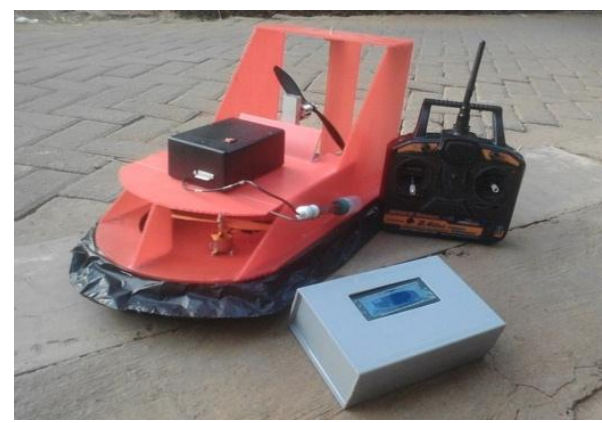

Figure 3. Assembled Hovercraft

According to the tests above, the utilization of 6 channels Transmitter Receiver can work perfectly to navigate the developed hovercraft. However, it is found in this experiment that this component only serves well before the hovercraft reach 1500 meters in distance without barrier. Hence, the hovercraft should be carefully navigated when it is operated over the flowing water environment because the flow of the water can drag the hovercraft away to out of reach distance. Another finding, although the combination between the developed hovercraft physical design (see Figure 3) and its designed speed in this research can solved stability problems during its movement, yet the water speed still has crucial influence on the hovercraft's maneuver stability. Hence, this research confirmed Dhale et al.'s [6] suggestion that hovercraft physical design and material selection have significat contribution to improve hovercraft's stability. In addition, the hovercraft speed that was set in this research is aimed to avoid physical damage when hovercraft crash hard objects such as stones.

\section{CONCLUSION}

The developed hovercraft has demonstrated the utilization of low cost and strong materials and has proved its capability as a carrier to transport an I-BE biosensor. Although using light materials, the hovercraft was succeeded to maintain its movement stability while running in its average moving speed. Moreover, the maneuverability performance indicates that the hovercraft's propellers and servo serve perfectly as propulsion and lifting systems. However, the battery duration was noticed as hovercraft's weakness since it only serves for approximately 20 minutes. And for the future research, it is recommended to add Proportional Integral Deritative (PID) controller for smoother navigation and to attach a wireless serial lines so that the hovercraft becomes more resistant to interferences, has greater bandwidth and longer distances.

\section{ACKNOWLEDGEMENTS}

This work was supported by the General Directorate of Indonesian Higher Education Indonesia (DIKTI-Indonesia) through competitive research grant number: 022/SP2H/LT/DRPM/II/2016.

\section{REFERENCES}

[1] Hardin PJ, Jensen RR, "Small-scale Unmanned Aerial Vehicles in Environmental Remote Sensing: Challenges and Opportunities", GIScience \& Remote Sensing, 2011 Jan 1;48(1):99-111.

[2] Watts AC, Ambrosia VG, Hinkley EA, "Unmanned Aircraft Systems in Remote Sensing and Scientific Research: Classification and Considerations of use", Remote Sensing, 2012 Jun 8;4(6):1671-92.

[3] Lelong CC, Burger P, Jubelin G, Roux B, Labbé S, Baret F, “Assessment of Unmanned Aerial Vehicles Imagery for Quantitative Monitoring of wheat Crop in small plots", Sensors, 2008 May 26;8(5):3557-85.

[4] McCormack ED, Trepanier T, "The use of Small Unmanned Aircraft by the Washington State Department of Transportation", Washington State Department of Transportation; 2008 Jun.

[5] Amiruddin AK, Sapuan SM, Jaafar AA, "Development of a Hovercraft Prototype with an Aluminium Hull base", International Journal of Physical Sciences, 2011 Sep 2;6(17):4185-94

[6] Dhale A, Ahuja A, Chanchal P, Gupta R, Kushwaha M, "Design and Development of Hovercraft", International Journal of Scientific Research in Science, Engineering and Technology, ISSN : 2394-4099, vol.2(2), pp. 709-712, 2016

[7] S.F. D’Souza, “Microbial biosensors, Biosens”, Bioelectron, vol. 16, pp 337-353, 2001 
[8] Bayram Ezgi, Akyilmaz Erol, "Development Of A New Microbial Biosensor Based On Conductive Polymer/Multiwalled Carbon Nanotube And Its Application To Paracetamol Determination", Sensors and Actuators B : Chemical, vol. 233, pp. 409-418, 2016.

[9] Anandhakumar A, Ganesan S, Goutham S, Pasupathi K, "Design and Fabrication of Hovercharft", International Journal of Innovative Research in Science, Engineering and Technology, ISSN: 2319 - 8753, Vol 4(6), 597-601

[10] Okafor BE, "Development of a Hovercraft Prototype", International Journal of Engineering and Technology, 2013 Mar;3(3).

[11] Tiwari. Amit, "To Study And Fabrication Of Air Cushion Vehicle", International Journal Of ResearchGranthaalayah, 3(3):March, 2015.

[12] Selma B, Chourqaui S, "Neural Network Navigation Technique for Unmanned Vehicle", Bulletin of Electrical Engineering and Informatics. 2014 September;3(3):195.

[13] Mohiuddin MS, "Performance Comparison of Conventional Controller with Fuzzy Logic Controller using Chopper Circuit and Fuzzy Tuned PID Controller", Indonesian Journal of Electrical Engineering and Informatics (IJEEI). 2014 Dec 1;2(4):189-200.

\section{BIORAPHIES OF AUTHORS}

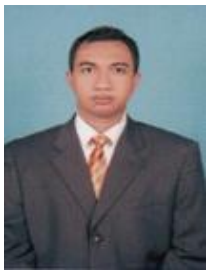

Rinta Kridalukmana was born in Semarang, Indonesia in 1977, he got his title as Computer Bachelor from Department of Information System in Stikubank Semarang in 2003 and Magister title from STEI ITB (School of Electrical Engineering and Informatics, Bandung Institute Technology) in 2007. Now, he is one of the members of Association for Computing Machinery and a lecturer at the Program of Computer System, Faculty of Engineering, Diponegoro University since 2008. The research field is in intelligent system, information system, mobile application and system integration.

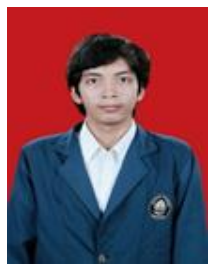

Budi Cahyo S.P. was born in Semarang, Indonesia in 1992. He is interested in programming and research about embedded engineering, especially robotic platform. He got his title as Computer Bachelor from Department of Computer Engineering in Universitas Diponegoro Semarang in 2016. The research field is in embedded system, robotic development and IoT application.

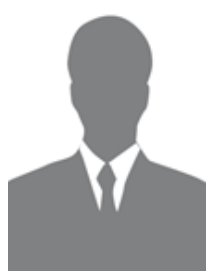

Deddy Kurniawan Wikanta was born in Semarang, Indonesia in 1952, he got his title in Chemical Bachelor Degree from Diponegoro University Semarang in 1979 as well as the Magister title in 2000. He has served Diponegoro University as a lecturer since 1981 at Diploma Program of Chemical Engineering, Faculty of Engineering. The research field is in chemical enzyme and its extraction.

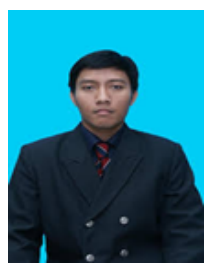

Fahmi Arifan was born in 1980 in Pemalang, Indonesia. In 2003, he graduated from Diponegoro University holding the title of Bachelor Degree in Chemical Engineering. Then, in 2010, he got his magister title from Gadjah Mada University. He is one of the lectures at the Diploma Program of Chemical Engineering, Faculty of Engineering, Diponegoro University since 2005. The research field is in chemical technology. 